\title{
ÀS MARGENS DO RIO: EDUCAÇÃO INTERCULTURAL E PROFESSORES INDÍGENAS
}

\author{
Renato Antonio Gavazzi*
}

\begin{abstract}
Resumo: Este estudo focaliza a questão ambiental como tema transversal da geografia no currículo dos cursos de treinamento para professores indígenas coordenados pelo autor no Parque do Xingu, habitado por quatorze grupos étnicos diferentes. A discussão do gerenciamento ambiental dos recursos hídricos em terras indígenas destaca aspectos pedagógicos e políticos, o problema das terras ocupadas por grandes propriedades e a contaminação da água e destruição dos rios decorrentes. Os cursos de treinamento estimulam os professores a procurar soluções para esses problemas ambientais. 0 autor pesquisa a participação da sociedade civil na formação dos Comité de Bacias Hidrográficas que integram a Política Nacional de Recursos Hídricos. Enfatiza a necessidade de uma educação ambiental multicultural que integre os estudantes indígenas e a sociedade brasileira como forma de identificar, como país, novas formas de relacionamento com o ambiente.
\end{abstract}

Palavras- chave: Interculturalidade; Ambiente; Educação indígena.

\section{Introdução}

0 meio ambiente é focado aqui como tema transversal da geografia nos currículos de educação escolar indígena ${ }^{1}$ na área de estudo da natureza e sociedade, dentro de processos educativos de cursos de formação para professores indígenas do Parque do Xingu. Nesse contexto de formação, a partir de uma perspectiva de educação diferenciada, bilingüe e intercultural, a educação ambiental parte de um problema concreto relacionado à gestão dos recursos hídricos da bacia do Xingu.

Os principais rios afluentes que formam a bacia do Xingu têm as suas cabeceiras fora dos limites demarcatórios do Parque e, portanto, estão sujeitos a todos os impactos ambientais da região. Nos últimos trinta anos, 0 desenfreado processo histórico da ocupação de frentes da agropecuária no entorno do Parque e a instalação de grandes fazendas de gado (e em número menor, de soja), de madeireiras e de alguns
0 Parque Indígena do Xingu é formado por vários rios. Todas as nascentes dos rios começam fora do limite e fica difícil de controlar os rios que pertencem a nós (KAYABI, 2000 ).

pequenos garimpos de ouro isolados vêm trazendo sérios problemas ambientais para as populações indígenas que ali vivem, e usam e manejam, milenarmente, de forma sustentável, os recursos hídricos dessa região do Brasil.

\section{Um pouco da história}

A criação do Parque Indígena do Xingu (PIX), em 1961, pelo presidente Jânio Quadros,

fundou-se em argumentos que procuravam conciliar uma perspectiva de conservação da natureza com a preservação cultural das etnias que lá viviam. E, de fato, 0 PIX é um oásis hoje ameaçado no meio de um processo galopante de destruição ambiental no seu entorno, incluindo as cabeceiras dos formadores do Xingu, todas excluídas da sua delimitação original ( VILLAS BOAS, 1996). 
Um dos principais problemas ambientais resultantes dessa ocupação é 0 assoreamento das nascentes formadoras da bacia hidrográfica do rio Xingu, devido ao grande desmatamento de matas ciliares às margens dos rios, riachos ou córregos que se encontram fora do Parque, realizado pelos fazendeiros e donos de madeireiras. Também são problemas ambientais, em menor escala, os pequenos garimpos e a contaminação de agrotóxicos das fazendas de plantações de soja. Além da destruição de seus rios, os índios enfrentam dificuldades diante da morosidade dos setores públicos federais na intervenção e solução desses problemas de impacto sobre o meio ambiente. É preciso lembrar que desmatamento de mata de galeria é crime ambiental, mas falta mobilidade, agilidade e força política para intervir e solucionar esse problema.

Um caso bastante relevante foi a luta do povo Suyá, um dos catorze grupos étnicos habitantes do Xingu, para a preservação de seu território. 0 conflito teve início no ano de 1990, com a contaminação das águas do rio Suiá- Missu pelas dragas de um fazendeiro que estava escavando o leito do rio Daro, afluente da margem esquerda. Em 1994, outro conflito relacionado às águas foi o de Santo Antônio, onde os Suyá paralisaram os trabalhos de desmatamento das fazendas São Pedro e Santo Antônio, localizadas próximas aos afluentes da margem esquerda do rio Suiá-Missu. Alarmados com a situação de deterioração de suas águas, começaram um movimento de luta e pelos seus direitos. Porém, esbarraram com outro grande problema: os "homens de Brasília", representantes dos órgãos oficiais do governo brasileiro, responsáveis pela questão indígena e ambiental no país, FUNAI/IBAMA, que não penalizaram os infratores em seus crimes ambientais. Cumpre notar que existe uma excelente legislação ambiental no Brasil, porém faltam decisões do judiciário e do executivo nas transformações estruturais capazes de regularizar as formas atuais de uso e abuso dos recursos naturais.

\section{Homem, natureza e sociedade}

Os grupos indígenas do Parque do Xingu não vivem a realidade da distribuição de água por torneiras e nem se preocupam com a limitação do uso desse líquido tão precioso e raro para outras sociedades. As águas dos rios passam constantemente em frente de suas aldeias, num eterno movimento de tempo de chuva e tempo de seca. 0 rio tem vida e dá a vida, mata a sede e a fome, lava o corpo, lava a roupa, leva as pessoas para todos os lugares, rio acima, rio abaixo. Essa relação das águas com a vida, com 0 mundo dessas sociedades indígenas é o resultado do longo processo histórico e cultural das relações entre essas sociedades e a natureza.

No lago Ipavu existem muitas coisas: estátuas antigas com desenhos dos animais, aves, peixes e homens. No lago existem muitos peixes como: tucunaré, pacu, piau, lambari, pintado, piranha... 0 lago usamos para atravessar até o outro lado para irmos para a roça, para pescar, para irmos para 0 posto Jacaré ou para outras aldeias. À direita e à esquerda do lago existem dois córregos, com as águas caindo dentro do lago. As águas dos córregos são sempre limpas, cristalinas. Nas suas bocas existem lambaris andando em cardume, que o pessoal pesca com a rede para aproveitar. 0 lago Ipavu é bastante grande, segundo a lenda dos avós, dizem que um rapaz estava recluso, estava tomando erva sagrada para ficar forte e ser grande lutador. Diz a lenda que o rapaz tinha um pombo de estimação, quando o rapaz estava tomando a erva, dizem que seu pombo veio sentar na beira da panela de barro, sem ser percebido pelo dono. 0 pombo tomou toda a erva da panela, só quando estava no fim que 0 dono percebeu e botou o pombo para fora. Esse pombo levantou vôo, foi bem alto, de lá vomitou toda a erva que estava no seu papo e encheu toda a aldeia. 0 pombo vomitou toda a erva formando o grande lago. Junto com a erva o pombo vomitou muitos bichos bravos nas águas, fazendo com que os bichos comessem todo o pessoal da aldeia, até o seu próprio dono. Mas, com a chegada dos brancos um dia na aldeia, dizem que eles mataram todos os bichos fera do lago, com armas de fogo e bomba. Dizem que era perigoso andar nesse lago, mas agora os bichos se esconderam. Mas de vez em quando atacam a gente! (Marcelo KUREHETE KAM AIURÁ, apud GAVAZZI, 1996).

0 professor indígena que escreveu o texto acima vê 0 lago Ipavu em todos os seus aspectos: político, econômico, social, cultural e ecológico. No aspecto político, a ocupação do território ancestral é atestada pelo lago, onde foram deixadas marcas das peças arqueológicas: as "estátuas antigas". O lago, por outro lado, enfocado no seu aspecto sócio-econômico, é usado para transportar o homem para 0 trabalho da "roça" e para "pescar", além de produzir o peixe. E o trabalho da pesca está relacionado à produção econômica da aldeia e à sobrevivência do grupo. As águas do lago, ainda no seu aspecto físico, biológico e ecológico, 
são um elemento isento de substâncias estranhas: "as águas dos córregos são sempre limpas, cristalinas", "com as águas limpa caindo dentro do lago", "existem lambaris andando em cardume". No aspecto mítico-cultural, fundamental para as sociedades indígenas, a origem do lago para os Kamaiurá está relacionada com 0 pombo, que tomou toda a erva sagrada e depois vomitou a erva e as feras. E fez assim surgir 0 lago Ipavu.

0 lago não é concebido como isolado de seu meio. Ao contrário, está em interação com o homem, não sendo um objeto de uso e transformação. Assim, o lago está intimamente inter-relacionado com o meio natural, seus componentes biológicos, sociais e fatores culturais, num constante movimento de inter-relação homem-natureza:

As sociedades indígenas têm uma relação diferenciada com o seu ambiente, e esta diversidade está intimamente relacionada a diferentes formas de organização social desses povos, e no que isso tem implicado, ao longo do tempo, em sua relação com a natureza (MAGALHÃES, 1994).

\section{Geografia e meio ambiente}

Como a geografia, no currículo de formação de professores indígenas, focando o tema transversal "meio ambiente", pode contribuir para a compreensão dos problemas relacionados aos recursos hídricos? A geografia pode ser estudada a partir de diferentes pontos que sejam de interesse para aquele povo, ou em nível mais local, para aquela comunidade: as terras, o céu, as matas, o território indígena, as águas. Um fértil exemplo de como se pode começar a estudar geografia são as águas.

Estudar os territórios a partir das águas não significa que não se vá estudar outros aspectos, mas é um dos caminhos pelo qual se pode avançar nesse estudo. A água é fonte de vida para todo mundo deste planeta e é um assunto importante para qualquer comunidade. Na Amazônia, tudo é feito ou pensado de acordo com as águas - as distâncias, 0 tempo, é contado 'rio abaixo, rio acima'... Em toda aldeia, a hora do banho é a hora mais alegre do dia; a água dá vida, faz brincar, ficar alegre. Os rios também muitas vezes formam os limites das Terras Indígenas. Nas cerimônias e rituais, quase sempre se necessita da água. $A$ água dá forma à terra, recorta a paisagem, desenha o planeta. E está cada vez mais difícil [...] (BRASIL, 1998).

Os grupos indígenas do Xingu perderam o controle e 0 manejo dos afluentes do rio Xingu nas suas terras tradicionais que ficaram excluídas da delimitação do Parque em 1961. Porém, hoje surgem como novas possibilidades a discussão, a criação e a participação indígena nos Comitês de Bacias Hidrográficas ${ }^{2}$. Os índios xinguanos podem assim voltar a ter o controle e o manejo dos rios formadores da bacia do Xingu no gerenciamento dos recursos hídricos.

0 novo processo do Gerenciamento dos Recursos Hídricos é um novo caminho aberto às organizações da sociedade civil, pois agora existe espaço para participar do processo de decisões, influindo na busca de soluções mais adequadas para os problemas locais e fiscalizando o governo (SÃO PAULO, 1997).

Nos cursos de geografia para formação de professores índios no Brasil atual, a educação ambiental vem incentivando a discussão e a reflexão com os professores os seus problemas concretos, como as formas de ocupação do espaço pela sociedade não-índia no entorno do Parque do Xingu. Além disso, tem identificado o problema do assoreamento dos rios, conseqüência das derrubadas das florestas e das matas ciliares protetoras das águas e das margens. Também vem analisando as conseqüências dos danos ambientais, identificando mecanismos de fiscalização e penalização dos responsáveis pelos problemas ambientais relacionados à degradação da bacia do Xingu. Nos dois últimos cursos de geografia para os professores indígenas do Parque, o tema da gestão das águas possibilitou intensas discussões. Os professores indígenas, por meio da cartografia, realizaram o Diagnóstico ambiental dos recursos hídricos da bacia do Xingu, procurando soluções viáveis para os problemas levantados. Fez-se, ainda, o estudo das leis de implantação e participação da sociedade civil na formação dos Comitês de Bacias Hidrográficas, hoje parte da política nacional de recursos hídricos, com a criação do sistema nacional de gerenciamento, regulamentado 0 inciso XIX do art. 21 da constituição federal (BRASIL, 1997).

Diante da dura realidade resultante dos conflitos de interesses econômicos e sociais relacionados à região, e da 
fragilidade do Parque do Xingu face ao processo de ocupação que vem se consolidando em seu entorno, como a geografia pode contribuir para que diferentes setores da sociedade desenvolvam ações conjuntas na gestão dos recursos hídricos?

É importante que os professores, em processo de formação, possam obter informações e conhecimentos sobre as interdependências econômicas, políticas e ecológicas no mundo moderno, para que compreendam a ocupação que está ocorrendo no entorno do Parque. A possibilidade de se discutir a política nacional de recursos hídricos, os direitos oriundos da lei em vigor, a preservação de um meio ambiente sadio, a defesa do patrimônio cultural e do potencial produtivo dos recursos naturais contribui para a formação do professor indígena como ator dinâmico, capaz de atuar nas transformações sociais e ambientais de sua região. A participação indígena na defesa do meio ambiente dependerá, no entanto, do respaldo de informações sobre seus direitos, especialmente o conhecimento da legislação ambiental. Só assim os índios podem obter maior eficácia política nas lutas que vêm sendo por eles travadas. Tais conhecimentos são ferramentas na defesa de seus direitos referentes à questão ambiental, de forma a contribuir para a resolução dos problemas relacionados aos impactos ambientais que hoje 0 Parque e seu entorno estão sofrendo.

0 mundo água, o mundo terra é igual um prédio que tem andares, o primeiro mundo está embaixo. Neste mundo existe muita terra boa, mas a água é completamente poluída de sangue, cabelo e pus.

0 segundo mundo é este que estamos vivendo aqui, tem pouca terra e muita mais água, mas tem pouca água para o consumo dos seres vivos. A maioria das águas são salgadas, e outra parte poluída, e a doce é para o consumo humano...

Alô mundo, eu estou preocupado! Vamos cuidar da nossa água, nós estamos matando o remédio da nossa vida. A água é o coração de todos os seres vivos.

As águas subterrâneas são os caminhos dos donos das águas, eles fazem as águas se movimentarem. Aonde eles não existem, os donos das águas, não há água, não há chuva. Os bichos donos das águas moram nas cabeceiras dos rios e nos olhos d'águas, são eles que soltam água para reabastecer os rios.

0 terceiro mundo fica lá em cima, que chamamos de céu, que existe terra e água. Sabemos que nesse mundo tem água especial, e existe matas e cidades.

0 quarto mundo onde fica a escuridão, também existem pessoas. Neste mundo não há sol, estrela, lua e nem clareira. As pessoas são negras.

Esta sabedoria são os sonhos dos pajés [...] (KAYABI, 2000).

\section{Pelas duas margens do rio}

Só iremos respeitar um outro povo conhecendo 0 diferente. (Joaquim KAXINAWÁ e Isaac ASHENINKA, apud GAVAZZI \& SPYER, 1998).

A educação ambiental, no contexto analisado, permite um vínculo estreito entre os processos educativos e a realidade, estruturando suas atividades em volta dos problemas reais que as comunidades indígenas vêm experimentando com a contaminação de suas águas. Nesse caso, o problema da gestão dos recursos hídricos é trabalhado com apoio da geografia. Porém os problemas ambientais num curso de formação devem também ser enfocados por uma perspectiva interdisciplinar e globalizadora. Num curso de professores indígenas, é imprescindível que as disciplinas de língua indígena e portuguesa, história, matemática, ciências, artes contribuam, a partir de outras ferramentas, para a construção das novas possibilidades de gestão dos recursos naturais dentro e fora dos territórios.

0 rio Preto e o rio Awaia Missú são afluentes do rio Xingu. Esses rios começam muito longe e existem problemas nesses rios. Esses rios estão sendo contaminados mais rápidos pelos os fazendeiros, madeireros e os pescadores. Os pescadores que pescam nos rios jogam plásticos, bichos mortos, latas vazias, cerveja descartável, etc. Contaminam o rio, não só o rio como também os peixes que vivem no rio, animais que vivem nas águas.

0 desmatamento também causa contaminação no rio. 0 rio Preto existem muitas fazendas na beira do rio para criar gado, o gado faz cocô e suja na beira do rio e igarapés.

Os afluentes do rio Preto estão ficando sujos e não dá mais para beber, porque estão contaminado pelo lixo, gado, ovelha, etc.

Os madeireiros também estão desrespeitando a lei, tirando madeira da beira do rio e do igarapé. Assim também 
contaminam 0 rio e a água perde 0 seu gosto, porque a cobertura dos rios foram todas desmatadas e fica aberta para qualquer pessoa estranha chegar nos rios para fazerem o querem com a água. Isso também causa assoreamento nos rios. Também tem fazendeiros que estão crescendo com as casas de alvenaria e jogando esgoto e lixo no rio. Essas pessoas que desmatam e poluem as águas não pensam e nem sabem o que vai acontecer com a saúde dos rios.

Os rios são importantes para todas as sociedades do mundo.

Os municípios que ficam nas nascentes dos rios jogam muito esgoto nos rios e a sujeira vem descendo pelo o rio. As pessoas que contaminam os rios, acham que nunca vão utilizar essa água e nem pensam no futuro (KAYABI, 2000).

Quando se trata da tolerância e cooperação entre diferentes sociedades, a educação ambiental deve contribuir para informar, dar consciência e construir novos tipos de valores e atitudes que colaborem para a convivência pacífica e para 0 respeito às diferenças culturais, sociais e econômicas. É importante que os alunos das escolas da cidade tenham acesso a outras formas de relacionamento com o meio que outras sociedades, como as indígenas, desenvolvem. Devem poder pensar que há outras formas de vida além das que eles conhecem, próprias ao universo urbano, com seus lixos, esgotos, fumaça, tráfego, poluição sonora e outdoors. A educação ambiental pode assim ajudar alunos e alunas da rede de ensino, sejam eles do campo ou da cidade, a refletir criticamente sobre a diferença entre os diversos povos do mundo; sobre sua relação com as águas, os rios e as florestas, sobre a capacidade de contemplação, de poesia e de saberes míticos. Dessa maneira, será fonte de informação sobre novas formas de vida, não predatórias e, ao mesmo tempo, estará criando valores e atitudes para a compreensão de outras maneiras de fazer, de novos/velhos modos de olhar o meio ambiente. Quando se dá informação sobre esses "outros" e se analisam suas ações e as conseqüências dessas ações, pode-se caminhar para a modificação dos modos de ocupação e utilização dos recursos naturais, de acordo com o princípio da sustentabilidade. Algumas das crianças que vivem nas cidades e nos campos, próximas ou não de modelos predatórios, são as futuras responsáveis pelo rumo das políticas nacionais e/ou locais, do meio ambiente, educação e saúde. Essas crianças estarão, no futuro, exercendo, como cidadãos brasileiros, 0 direito às práticas políticas dos níveis mais importantes. A educação ambiental abre possibilidades para a formação de uma nova consciência, um universo renovado de valores da humanidade em geral.

É importante, assim, que se possa lutar, nos processos democráticos, por políticas públicas que possibilitem que as escolas não-indígenas, da cidade e do campo, recebam materiais didáticos produzidos pelos professores indígenas, livros em que eles relatam e registram seus conhecimentos, as formas como suas sociedades interagem com o meio ambiente, a exemplo dos textos incluídos neste trabalho.

A interculturalidade que reúne processos de formação dos professores índios à educação em geral é a possibilidade de alunos e professores de pequenas sociedades tribais ampliarem os mecanismos de defesa do seu meio ambiente e, ao mesmo tempo, produzirem conhecimentos e contribuírem para ampliação das lutas da sociedade civil na defesa do planeta, usando como instrumento a nova legislação ambiental, produto e resposta aos vários problemas vividos pela sociedade nacional e internacional em relação ao meio ambiente. No caso que aqui apresentei, como em outros, a educação intercultural experimenta um amplo caminho de duas vias: como as águas, que vão e vêm pelas duas margens do rio. $\mathrm{Na}$ ida, passa por terras indígenas. $\mathrm{Na}$ volta, irriga cidades e campos. Dos níveis locais até os mais globais, passando do comunitário ao municipal, estadual e até internacional.

Os processos educativos que visem à formação de uma nova consciência ambiental, a partir do conhecimento do "outro", são um dos mecanismos atuais para a urgente transformação do quadro de deterioração do meio ambiente e de degradação dos valores e atitudes relacionados à preservação da natureza e do homem.. Nesse caso, a educação intercultural experimenta um amplo caminho de duas vias: como as águas, que vão e vêm pelas duas margens do rio. $\mathrm{Na}$ ida, passa por terras indígenas. $\mathrm{Na}$ volta, irriga campos e cidades. 
GAVAZZI, R. A. (2001) By the river banks: intercultural education and indigenous teachers. Revista do Departamento de Geografia, n. 14, p. 33-38.

\begin{abstract}
This study focuses on the environmental issue as a transversal subject of geography in the curriculum of the training courses of indigenous teachers coordinated by the author in the Xingu Park, where fourteen different ethnic groups live in. Pedagogical and political aspects of environmental management of water resources in indigenous lands are stressed, focusing on problems of land occupation by large properties and the resulting water contamination and river degradation. Training courses aim to stimulate teachers to find solutions for environmental problems. The author studies the participation of civil society in the formation of Water Basin Committees, presently a part of the National Policy for Water Resources. The author emphasizes the necessity of an intercultural environmental education directed to young students of indigenous societies and the Brazilian society as well so that we may identify as a country new relationships with the environment.
\end{abstract}

Key words: Interculturality, Environment, Indigenous education.

Recebido em 7 de agosto de 2000, aceito em 28 de janeiro de 2001.

\section{Referências bibliográficas}

BRASIL. Ministério do Meio Ambiente e da Amazônia Legal. Secretária dos Recursos Hídricos (1997) Lei n 9.433, de 8 de janeiro de 1997. Política nacional de recursos hídricos. p. 12-35.

BRASIL. M inistério da Educação e do Desporto (1998)

Referencial curricular nacional para as escolas indígenas.

Área de estudo da cultura e da natureza: geografia. 230p.

GAVAZZI, R. A. (org.) (1996) Geografia Indígena. Brasília, Instituto Socioambiental/Ministério da Educação e do Desporto, 30p.
GAVAZZI R. A.; SPYER, M. R. (orgs.) (1998) Atlas geográfico indígena do Acre. Rio Branco, Comissão Pró Índio do Acre/ Ministério da Educação e do Desporto. 20p.

KAYABI, A.(2000) Textos produzidos no V Curso Geografia do Parque Xingu. Parque Indígena do Xingu. [não publicado]

MAGALHÃES A. C, (org.), (1993) Sociedade indígenas e transformações ambientais. Belém, NUMA - UFPA, 19p.

SÃO PAULO (Estado) Secretaria do M eio Ambiente. Secretaria de Recursos Hídricos, Saneamento e Obras (1997) Gestão das Águas: 6 anos de percursos. 13p. 